\title{
INCIERTAS ESTANCIAS. VERSO LIBRE, REGULAR E IRREGULAR EN EL PRIMER NERUDA
}

\author{
Ángel Luis LujÁn ATIENZA
}

Resumen: Este artículo se plantea, a partir del estudio de la métrica del primer libro de Pablo Neruda, Crepusculario, y el exhaustivo repertorio de formas métricas empleadas en él un doble objetivo. Por una parte, se constata, como aportación a la historia de la literatura del Post-modernismo hispanoamericano, la tendencia del primer Neruda a experimentar sobre patrones métricos pertenecientes al Modernismo sin avanzar hacia las formas renovadoras de la vanguardia ya en vigencia en su tiempo. En el plano de teoría métrica, este estudio pretende aportar algunas consideraciones sobre el controvertido deslinde entre verso libre y versificación regular e irregular. A este respecto, y partiendo del ejemplo de Crepusculario, se hace una clara distinción entre verso libre, formas estróficas sancionadas por la tradición, formas regulares inventadas por el poeta y formas irregulares que no pueden considerarse verso libre.

Palabras clave: Pablo Neruda, Crepusculario, métrica, Postmodernismo, verso libre.

Abstract: This paper focuses on the metrical forms of Pablo
Neruda's first book, Crepusculario, and contains a complete repertory
of the metrical patterns used there. As a consequence of the close
attention to these forms we can conclude: first, at the level of Literary
History, the tendency for traditional metrical patterns and their
experimental combination in Neruda's early works and his avoiding
of the innovative avant-garde metrics of his time; and, second, at
the level of metrical theory, a demarcation of free verse, regular and
irregular versification is suggested, so that free verse is not a kind 
of irregular verse, and regular verse can be divided into traditional metrical forms and regular forms invented by the poet. Irregular verse is not regular neither free verse.

Key Words: Pablo Neruda, Crepusculario, metrics, PostModernism, free verse. 
Tras las inciertas estancias de «Nocturno», Neftalí exhibe grande e inmediata seguridad estructurante en «Mis ojos» con sus cuartetos de pie quebrado (en cierto modo anómalos porque el eneasílabo supera la mitad de las sílabas métricas de los tres alejandrinos); en «De mis horas» con el primer soneto nerudiano que conocemos; y en «Primavera» con sus dísticos pareados. No deja de sorprender que los más tempranos poemas de Neftalí anuncien ya versos y modelos estrófico que Neruda adoptará con gran éxito en el futuro: por ejemplo, los dísticos romanceados en el poema 20 y en «La canción desesperada» de Veinte poemas; los cuartetos de pie quebrado (variante sáfico-adónica) en «Ángela adónica» y en «Alberto Rojas Giménez viene volando» de Residencia; y sonetos habrá muchos de grande maestría, incluyendo un entero libro con Cien sonetos de amor (Hernán Loyola, en Neruda, 2000-2002: IV, 1218-9).

M UCHO se ha escrito sobre Pablo Neruda y muy poco sobre su métrica. En la bibliografía más actualizada que conozco sobre el poeta no aparece siquiera la métrica como tema en el índice que ordena los trabajos recogidos (Woodbridge y Zubatsky, 1988) ${ }^{1}$. No obstante, Neruda se presenta como un poeta especialmente interesado en los problemas del ritmo y en la renovación de la métrica española, tanto en sus primeros momentos superadores del Modernismo como en la contribución a implantar en la tradición hispana el versículo libre con la contundencia de dos libros como Residencia en la tierra y Canto General. Ese afán renovador lo emparenta con Rubén Darío, con el que compartía un perfecto oído para los matices rítmicos y la facilidad para la rima.

\footnotetext{
${ }^{1}$ Sobre la métrica de Neruda puede verse: Tavani, 1964; Loyola, 1996. Sobre Crepusculario, con alguna referencia a su métrica: Concha, 1972, 1974; Montes, 1967, 1974; Acuña, 1979.
} 
Ha sido Jaime Concha (1974) quien ha puesto de manifiesto la pertenencia de Crepusculario al postmodernismo con razones en que pesan grandemente las características métricas del libro. No obstante, sufrimos todavía de una inexplicable desatención por toda la métrica de ese período (no sólo la de Neruda), aunque ésta constituye el eslabón fundamental para explicar el paso de la métrica regular al verso libre en la historia de nuestra literatura. Precisamente, el problema de la distinción y el deslinde entre métrica regular e irregular y verso libre es uno de las cuestiones que quiero tratar aquí a propósito de la métrica del primer Neruda.

La distinción entre métrica regular, irregular y libre es un terreno que está todavía sin delimitar con claridad y sometido a debate. Antonio Quilis (1984: 46) iguala versificación irregular y libre. Domínguez Caparrós (1993: 53-59; 2005: 92) incluye el verso libre dentro de la versificación irregular, según la postura más extendida (Paraíso, 1985). Navarro Tomás (1974: 39) considera igualmente el verso libre dentro del irregular tomando como unidad de medida el verso aislado, aunque para hablar de igualdad silábica tenga que remitir irremediablemente a la comparación con los demás versos de la composición: «Son libres los versos amétricos que no obedecen ni a igualdad de número de sílabas ni a uniformidad de cláusulas». Utrera Torremocha (2001: 10-13) agrupa el verso libre dentro de los tipos de versificación irregular, aunque sitúa su explicación en el terreno de la evolución de las formas métricas.

Para realizar esta clasificación, los autores toman, según se acaba de ver, como base la unidad versal con sus características silábicas y acentuales: sería verso libre, entonces, el que no se ajusta a ningún patrón silábico-acentual transmitido por la tradición. Habría que distinguir, no obstante, entre verso libre y versificación libre, como hace Domínguez Caparrós atribuyéndoles distintas entradas en su Diccionario de métrica española: «verso libre.1. Clase de verso irregular caracterizado porque la falta de regularidad en el número de sílabas no es sometida a ningún límite ni a ninguna norma acentual» (2004: 473); «versificación libre. 1. Clase de versificación irregular en que la falta de igualdad —o regularidad - en el número de sílabas de los versos no 
está sujeta a ningún límite ni a ninguna norma acentual» (2004: 452). Según vamos a ver, será necesaria esta distinción entre verso y versificación para hacer manejable y operativa una definición y diferenciación de métrica regular, irregular y libre, pues tal objetivo sólo se conseguirá si nos fijamos en el conjunto de la composición o en la unidad estrófica como patrón de medida y no en el verso aislado, que no puede tener características propias fuera de su inserción en una unidad más amplia.

Jaimes Freyre, en su clásico tratado de métrica, empieza considerando el criterio tradicional basado en la descripción del verso como unidad métrica para caracterizar el verso libre, pero acaba definiendo a éste como «la mezcla arbitraria de versos de períodos prosódicos diferentes y aun la combinación de frases sin ritmo regular alguno. Este es el verdadero verso libre») (1912: 114). Como se ve, el boliviano se da cuenta de que debe tomar no el verso aislado sino la secuencia de versos para calificar de libre una composición. Es lo que deja claro Lugones, que más en concreto habla, en el «Prólogo» a Lunario sentimental, del conjunto estrófico como unidad para medir la libertad del verso: «El verso al cual denominamos libre, y que desde luego no es el blanco o sin rima, llamado tal por los retóricos españoles atiende principalmente al conjunto armónico de la estrofa, subordinándole el ritmo de cada miembro, y pretendiendo que así resulta aquélla más variada» (1988: 95).

Considero, por tanto, que más que de verso libre habría que hablar de versificación libre para evitar mezclar los dos criterios antes expuestos. Un endecasílabo perfectamente tradicional puede estar incluido en un poema escrito en verso libre (como ocurre a menudo en Neruda y Aleixandre); a la vez, un verso que difiere de los patrones tradicionales puede formar parte de una composición regular en todos los demás aspectos. Por ello, creo conveniente dejar claro desde el principio que tomaré la estrofa o la serie de versos (depende de la composición) como patrón para la regularidad o irregularidad del verso.

Opino, además, que habría que pensar, como me propongo estudiar en la métrica del primer Neruda, no en una dicotomía entre verso regular e irregular sino en un paso gradual desde la irregularidad a la regularidad, hasta que se traspasa por fin la 
frontera del verso libre. Vamos a ver cómo Neruda juega con diversas clases de irregularidad por aproximación a un esquema regular, que no constituyen, en mi opinión, ejemplos de verso libre. La métrica irregular necesita a la métrica regular como medida de sus transgresiones, la versificación libre, sin embargo, no se opone a la regularidad (no la precisa para definirse) sino que está al margen de ella. Navarro Tomás apunta a este análisis, pero de manera más radical al considerar que el verso completamente libre «cae en realidad fuera del propio concepto de verso, no por lo que tiene de amétrico sino por su falta de ritmo» (1982: 386).

Estudiaré en este artículo la métrica del primer Neruda, centrándome principalmente en Crepusculario y pasando después a un rápido análisis de los cuadernos anteriores a la publicación de su primer libro, donde Neruda dejó constancia de sus iniciales ensayos poéticos ${ }^{2}$. A la vez que propongo este deslinde entre verso regular, irregular y libre el estudio arrojará luz sobre la renovación que Neruda pretende hacer del panorama métrico del Modernismo y postmodernismo, con implicaciones, por tanto, en la historia y crítica literarias.

\section{La métrica de Crepusculario}

Cito a continuación como punto de partida la breve (y única creo) descripción métrica de Crepusculario, que hizo Hugo Montes (1974: 6-8):

El libro muestra una clara tendencia a la métrica tradicional: dísticos pareados ("Melisanda", "El estribillo del turco"), dísticos blancos ("Farewell", "La muerte de Melisanda"), cuartetas asonantes ("Dame la maga fiesta", "Aromas rubios en los campos de Loncoche", "Aquí estoy con mi pobre cuerpo", "Hoy, que es el cumpleaños de mi hermana") y consonantes ("Tengo miedo", "El pueblo"), tercetos endecasílabos no concatenados por la rima ("El padre"), romances en terminación aguda ("Me

\footnotetext{
${ }^{2}$ Citaré las obras de Neruda por la edición de Obras Completas preparada por Hernán Loyola, Barcelona, Galaxia Gutenberg, 2000-2002, 5 vols. Crepusculario se encuentra en el tomo I y los cuadernos en el tomo IV. Citaré dando número de tomo y de página de la edición de referencia.
} 
peina el viento los cabellos") y cuatro sonetos de versos alejandrinos, conforme a las tendencias modernistas del filo del siglo ("Esta iglesia no tiene', "Pantheos", "Viejo ciego, llorabas", "El nuevo soneto a Helena"). El verso libre aparece con timidez y en composiciones poco relevantes ("Puentes", "Los jugadores"), siempre en arte menor. Mas dentro de este marco tradicional sobresalen dos notas precisas, a saber, la acusada variedad métrica y una gran independencia frente a exigencias retóricas absolutas. En los sonetos, por ejemplo, riman eraesperas, naciera-ciega, dijo-hijos, etc. A menudo varían las estrofas dentro de un mismo poema. Hay composiciones, como "Barrio sin luz", en que los versos asonantes van de dos en dos en el cuarteto inicial y pasan a la fórmula $\mathrm{ABAB}$ en el segundo, con la variante de una consonancia rica [...]. Los serventesios regulares del poema "Saudade" se interrumpen bruscamente al final; en vez de las catorce sílabas aparecen las tres de la palabra del título. Algo similar al añadido "Pero ella vive aquí" de "El pueblo". Hay poemas -"Agua dormida"-que constan sólo de un verso y los hay relativamente extensos.

Esta libre regularidad métrica, si se permite la paradoja, va a ocurrir, aunque en menor grado, en los Veinte poemas, para desaparecer en los libros siguientes [...].

Este recuento tan externo tiene una significación señalada: el alejamiento decidido de Neruda de los moldes modernistas externos, que lo atrapan apenas en su primer libro. En él se da la misma evolución que en Gabriela Mistral, cuyo Desolación (1922) está encuadrado en la retórica de Rubén y cuyos poemarios de madurez (Tala y Lagar) ocurren a través de formas depuradas, muchísimo más personales, menos de escuela. Si se compara la métrica recién presentada de Crepusculario con (7-8) la agilidad y la exigüidad de las Odas elementales se tendrá a la vista igual aunque más acentuado proceso de un verso $\mathrm{y}$ unas estrofas propios.

Hugo Montes habla de libre regularidad métrica y quizá sea esta una buena fórmula para definir al Neruda inicial. No obstante, su descripción no es ajustada en algunos puntos. Los de «Farewell» no son dísticos blancos ni son todos dísticos; igualmente «La muerte de Melisanda» no está formada por dísticos blancos, sino asonantados como los de «Farewell». «El estribillo 
del turco» no está compuesto en su totalidad por pareados; y «Puentes» no es un ejemplo de verso libre, sino de silva, y no en arte menor.

A pesar de esta libre regularidad y pese a las libertades que se toma con la métrica que hereda del Modernismo, es verdad que Neruda hace, como dice Montes, un libro que tiende a la métrica tradicional. El propio Neruda encabeza su obra con un epígrafe muy significativo sobre el anacronismo del libro, que hay que extender al terreno métrico, como una voluntad consciente de forma. Neruda estaba al corriente de las nuevas modas y patrones métricos, había leído a Sabat Ercasty, tenía que conocer las novedades prosódicas y gráficas del verso de Huidobro ${ }^{3}, \mathrm{y}$, sin embargo, opta por un verso y un lenguaje en gran medida continuador de Darío, y lo hace de manera premeditada, ya que repite la misma fórmula en los Veinte poemas de amor. Parece, pues, que Neruda, en su primera etapa, se adhiere voluntaria y conscientemente a un tipo de discurso poético que estaba a punto de periclitar. Sin atender a las novedades de las vanguardias, continúa la estela del modernismo quizá para demostrar que la forma puede ser cambiada desde dentro.

Antes de entrar en posteriores distinciones, se puede destacar que el verso predominante en el libro es, sin duda, el alejandrino, usado a la manera modernista, y las estrofas preferidas son los cuartetos de rimas alternas (serventesios), privilegiados también por Rubén Darío, el primer Huidobro y la poesía romántica y simbolista francesa en general, y los dísticos. Jaime Concha llega a hablar en este aspecto del «carácter de poesía escolar que el libro ofrece» (1972: 84).

En líneas generales, se puede observar la recurrencia de la consonancia imperfecta que no tiene en cuenta la $-\mathbf{s}$ final a efectos de rima, como ocurre en Gabriela Mistral y en Vicente Huidobro, por lo que no se puede considerar peculiaridad de la poesía nerudiana ${ }^{4}$. Sí llaman la atención algunos hiatos que

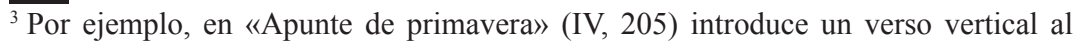
modo de los de Huidobro, lo que indica que Neruda conocía las innovaciones de las vanguardias pero no las quiso aplicar de manera generalizada.

${ }^{4}$ Lo comenta Navarro Tomás en relación con Gabriela Mistral: «Su percepción del verso se fundaba naturalmente en la imagen oral de la palabra, y es en realidad valioso como sello de su espontaneidad el hecho de que en su caso, como en el
} 
encontramos en estos poemas, como en el titulado «Viejo ciego, llorabas», que no hace sinalefa en el v. 1: «cuando tu vida-era» (tampoco en el borrador del mismo poema: IV, 199-200).

Para estudiar las formas métricas de Crepusculario conviene dividirlas en tres tipos, según he anunciado: los poemas en verso regular (aunque sea una regularidad marcada por el propio poeta), los poemas de versificación libre y los que tienden hacia la regularidad sin ser regulares en sentido estricto, los verdaderamente irregulares.

\section{Los poemas regulares}

Dentro de los poemas regulares tenemos que distinguir los poemas regulares de la tradición (lo que habitualmente se conoce como métrica regular) y los poemas regulares en que el patrón métrico procede de la invención del propio poeta. En efecto, la métrica tradicional no es más que un conjunto de estructuras regulares que han tenido un desarrollo histórico privilegiado de entre las posibles formas regulares a que daría lugar la libre combinatoria de tipos de versos y patrones de rima. No hay que confundir, por tanto, regularidad con métrica tradicional; confusión que impediría, entre otras cosas, dar explicación de la creación de nuevos patrones métricos regulares que con el tiempo, por repetición en el uso por parte de distintos autores, pasan a formar parte del repertorio tradicional.

Entre los patrones tradicionales, los sonetos alejandrinos, una de las formas preferidas del modernismo hispánico, forman un bloque característico al inicio del libro con una clara intención de situar su escritura en una tradición bien definida. Hay que hacer notar que después esta estrofa no vuelve a aparecer en el resto del libro. Se trata, además, de sonetos dispares por su temática y tono, y lo único que los aúna es la forma métrica, lo que nos sugiere que Neruda pretende establecer una continuidad con el Modernismo basada principalmente en aspectos formales

de Rubén Darío, las rimas de sus versos reflejan a veces subrepticiamente rasgos de su habla como el seseo y el yeísmo, y como la supresión o 'evaporación' de la $s$ final, a lo cual se refirió la autora en Tala comentando el uso de 'albricia' por 'albricias'» (Navarro Tomás, 1982: 321). 
al principio de su libro. Dos sonetos se titulan, de manera peculiar, no con el primer verso sino con el primer hemistiquio: «Esta iglesia no tiene» y «Viejo ciego, llorabas», de manera que Neruda parece atender más a la forma que al contenido al elegir títulos truncados sintácticamente pero completos en el plano métrico.

En un análisis más detenido de los poemas, vemos que «Pantheos» está creado sobre «Lo fatal» de Rubén Darío, que no es un soneto pero que tiende al soneto, por lo que se puede decir que Neruda saca lo que de soneto tiene el poema del nicaragüense. Por otra parte, esta pieza no tiene más peculiaridad que la neutralización de la $-\mathbf{s}$, pero esta vez usada no sólo como plural (rima: somos-como). "Viejo ciego, llorabas», por su parte, no tiene más peculiaridad que el hiato que he señalado y alguna irregularidad en la rima: «naciera/ciega» que rompe la consonancia, con lo cual vemos que incluso en las composiciones más regulares el poeta se permite algunas licencias.

Después de esta serie ya no vuelven a aparecer más sonetos en todo el libro. Se puede decir que Neruda ha situado uno de los metros más representativos del Modernismo al inicio de su libro, como un signo de que se adhiere a la tradición y a la estética que le precede, la conoce, y a la vez se propone superarla desde dentro.

La estrofa regular más abundante en el libro, con una gran tradición en el Modernismo, es el serventesio en alejandrinos, o cuarteto de rima alterna. Los tenemos en «Ivresse», que presenta no obstante una irregularidad: los versos 9 y 12 sustituyen el alejandrino por dodecasílabos asimétricos que invierten el ritmo de seguidilla: (5+7), lo cual es una novedad, pues se esperaría el ritmo usado por Rubén Darío en «Elogio de la seguidilla»:

Es bello porque nosotros lo bebemos

en estos temblorosos vasos de nuestro ser

que nos niegan el goce para que lo gocemos.

Bebamos. Nunca dejemos de beber.

Nunca, mujer rayo de luz, pulpa blanca de poma 
En efecto, sería más raro interpretar los versos señalados en cursiva como compuestos de $8+4$, cómputo también posible, pero que rompería el ritmo impar. El análisis de estos versos como compuestos de 5+7 es factible porque el ritmo alejandrino nos acostumbra a la cesura y su efecto es el de un primer hemistiquio al que le faltaran dos sílabas. Y precisamente en el verso 13 lo que encontramos es una anacrusis de dos sílabas, ya que el pretendido alejandrino resulta ser compuesto de 9+7: al primer hemistiquio se le ha añadido, al parecer, el adverbio «nunca» que abre el verso. Este poema, el único con este patrón métrico en la primera parte del libro, se sitúa aquí y cerca de los sonetos probablemente por afinidad de contenido, ya que trata un tema literario tomado de Dante. Observamos, además, un paralelo en esta misma sección en el poema «El castillo maldito», que cierra esta parte, construido también con serventesios, pero no en alejandrinos sino en versos compuestos de $8+8$.

«Aromos rubios en los campos de Loncoche» está escrito en serventesios alejandrinos, con la particularidad de que la rima es asonante, excepto al final: noche / Loncoche. Es el único poema de este tipo en la sección «Farewell», pues la mayor parte de los poemas en serventesios se acumulan en la parte central de «Los crepúsculos de Maruri»: «Dame la maga fiesta», «Saudade», que tiene la particularidad de que el verso final está compuesto por una sola palabra, la que da título al poema; «Aquí estoy con mi pobre cuerpo», «Hoy que es el cumpleaños de mi hermana» (esta vez no titulados con el corte del hemistiquio), y «Mujer, nada me has dado». Todos son regulares, formados por cuartetos alejandrinos de rima alterna, como "Tengo miedo», en el que el último verso aparece separado de los demás, aunque es un mero gesto gráfico, pues está claro que métricamente pertenece al cuarteto anterior.

La sección «Ventana al camino» recoge otros serventesios, pero no predominantemente alejandrinos, como «Campesina», compuesto por endecasílabos, con la peculiaridad de contar con tres endecasílabos dactílicos (acentos en cuarta y séptima): los versos 1, 6 y 10 (que aparecen así desde los borradores: IV, pp. 177 y 194). «El pueblo» conserva la regularidad de cuartetos alejandrinos con rima alterna, excepto por el añadido de una coda: «pero ella vive aquí», de gran efecto expresivo. 
«El coloquio maravillado» del ciclo de «Pelleas y Melisanda» está compuesto por seis serventesios alejandrinos, pero al tratarse de un poema dialogado, las estrofas se reparten entre las intervenciones de los dos personajes y no de forma simétrica, sino encabalgándose, de manera que la andadura de los serventesios está sincopada y la pura regularidad se ve relajada por el desigual reparto de los versos de las estrofas.

El conjunto de poemas estudiados forman el núcleo duro de las estrofas regulares tradicionales que integran este libro, y hemos podido comprobar que incluso en esta regularidad tradicional el poeta introduce pequeñas variaciones que liberan la rigidez de las formas y abren caminos para romper la tradición.

Fuera de estas dos formas prototípicas, podemos encontrar estrofas regulares en «Mancha en tierras de color», formado por dísticos dodecasílabos $(6+6)$, entre los que se mezcla algún alejandrino, con rima en los pares en las dos primeras estrofas y monorrimos consonantes el resto, formando pareados; «Poema en diez versos» está compuesto por cinco dísticos de rima consonante en los pares y diversidad de medidas, con predominio del alejandrino (sólo varía un eneasílabo y un endecasílabo); «Melisanda» está compuesto por dísticos en alejandrinos monorrimos, esto es, pareados sin ninguna particularidad; «El padre» está compuesto por tercetos endecasílabos sin encadenar de rima asonante, variante que viene documentada en el Repertorio de Navarro Tomás (1968: 28-31) en Ricardo Jaimes Freyre (aunque en éste con rima consonante) y parece ser usual en Manuel González Prada. «El encantamiento» es un terceto alejandrino, con la única particularidad de que es raro encontrar en la tradición un terceto aislado; $y$, por último, «Puentes» es una silva arromanzada, que mezcla endecasílabos y heptasílabos, con un alejandrino en el verso inicial.

\section{Poemas completamente libres}

Frente a la regularidad de las estrofas analizadas que incluyen a Neruda en la corriente modernista más claramente, el verso libre es todavía tímido en este libro. De hecho, está presente sólo en dos poemas, pero llamativamente uno de ellos es el que 
cierra el libro. Como he dicho, considero versificación libre a la que está al margen de toda regularidad, por lo que no se puede considerar dentro de la versificación irregular: no se mide con respecto a ningún patrón regular, sino que se establece al margen de ellos. Veamos los ejemplos de Neruda.

«Los jugadores» abandona toda regularidad, incluso la rima, que es persistente en esta etapa de la poesía de Neruda. Se basa en algunas repeticiones y llamativamente acaba dos de las estrofas con claros heptasílabos: «cantó bellas canciones» y «que no precisa fin». El deseo de cerrar series con medidas conocidas hace que la clausura final del poema esté compuesta por un dístico de alejandrinos: «Los miro entre la vaga bruma del gas y el humo. / Y mirando estos hombres sé que la vida es triste». Parece como si el poeta quisiera que el lector reconozca una medida estable en el cierre que dé sensación de clausura frente a la libertad del resto del poema que no contempla ninguna regularidad.

Sin embargo, lo más significativo es que todo el poemario se cierre precisamente con un poema de versificación libre. Se trata de una silva libérrima impar, en terminología de Isabel Paraíso, que juega con diversas asonancias de modo arbitrario. Se detecta una clara tendencia hacia la familia del endecasílabo, a pesar del uso de diversos ritmos. Por ejemplo, el verso «se mezclaron voces ajenas a las mías» no puede reducirse a ninguna medida tradicional, y pone de manifiesto perfectamente la ajenidad de las voces. Los versos «cuando era mi corazón / una corola de llamas» son dos octosílabos claros en medio de versos de signo impar: se sitúan entre eneasílabos. Tampoco es posible encontrar un patrón que explique los versos: «lo sintiera con los oídos o con los ojos», «Vinieron las palabras y mi corazón» ni «incontenible como un amanecer».

Sin embargo, el final se apoya en cuatro claros alejandrinos, confirmando que existe una tendencia a cerrar las series poemáticas más libres con patrones métricos muy fijos para dar al lector sensación de cierre estable. Este poema ejemplifica perfectamente a lo que quiero apuntar cuando digo que la medida de la libertad no es el verso sino la estrofa o el conjunto poemático, ya que contiene versos perfectamente regulares, y sin embargo es la aparición entre estos versos regulares de líneas que no se 
pueden regularizar y la libre combinación de versos regulares y libres en estrofas que no guardan proporción lo que lo convierte en un poema en verso libre. No es que se rompa la regularidad, como ocurre en el verso irregular que veremos a continuación, simplemente no la tiene en cuenta.

El otro hecho que quería destacar es que Neruda elige precisamente la versificación libre para escribir una poética, que es paralela a la del poema «Inicial» que sirve de pórtico al libro. Pareciera que cuando accedemos al discurso sobre la propia poesía, a la metapoesía, la expresión necesitara desligarse de toda constricción y el poeta hablar desde la exterioridad de las rigideces del metro fijado y de la tradición. Cuando el poeta hace poesía se puede ajustar a otros modelos, pero cuando habla de poesía lo hace desde la máxima libertad creadora. Esta estrategia parece sugerir la idea de que el impulso creador (externo) es libre aunque se plasme en formas tradicionales (internas). De ahí precisamente que cuando se alude a las «palabras ajenas», las que vienen dictadas por la tradición, se haga desde la expresividad sin constricciones del verso libre, es decir como una manifestación de la voluntad del poeta de someterse a la ajenidad de las voces no por imposición sino desde una actitud liberadora.

Vemos, pues, que si el inicio se marcaba con rotundidad métricamente, para el final se reserva un poema en verso libre que anuncia la evolución posterior de la poesía de Neruda. Desde los sonetos alejandrinos iniciales a la versificación libre del poema «Final», el itinerario del libro marca un paso de la rigidez de la tradición a la liberación de la forma, aunque después Neruda no sea inmediatamente fiel a este itinerario trazado.

\section{Los poemas irregulares}

Entre los dos extremos que acabamos de ver: formas regulares tradicionales (con alguna anormalidad) y las escasas formas completamente libres de Crepusculario se sitúa toda una serie de poemas que fluctúan en torno a la regularidad sin alcanzarla, y que por ello llamaré propiamente irregulares. Se trata de ese tipo de composiciones que llama la atención a Hernán Loyola y que califica de inciertas estancias, como se ve en la cita que 
abre este trabajo, y que ocupan gran parte del texto de Crepusculario.

Se impone distinguir entre versificación irregular y libre por la sencilla razón de que si incluyéramos el verso libre dentro del irregular no habría manera de dar cuenta de estas composiciones de las que voy a hablar a continuación y que se caracterizan precisamente por romper una regularidad, bien la de la métrica tradicional, bien la marcada o inventada por el propio poeta. De esta manera, tenemos por un lado la métrica regular, caracterizada por la presencia de unas pautas silábicas y de rima que se repiten, de manera reglada, a lo largo de una composición, dentro de las cuales se incluirían las formas que la tradición ha perpetuado (métrica regular tradicional); y por otra parte, y en distintos grados, la métrica irregular que partiendo de modelos regulares los altera de diversas maneras, pero conservando el carácter métrico de las composiciones. La versificación libre estaría fuera de esta clasificación ya que no sería irregular, sino amétrica, pues se opondría tanto a la regularidad como a la irregularidad.

La irregularidad se puede ejercer no sólo sobre patrones métricos tradicionales sino sobre una regularidad creada por el propio poeta. En esto último estriba, creo, gran parte de la originalidad de Neruda en este primer libro. Como vamos a ver, en ocasiones Neruda parece establecer una regla propia como patrón estrófico para un poema, y él mismo acaba variando el diseño métrico en el discurrir del discurso sin llegar a caer en el verso libre en tanto que siempre hay una fluctuación en torno a la regularidad inicial. La sensación que da es la de un verso no acabado, un discurso no cerrado, como si el poema no fuera más que una aproximación al poema ideal, con lo que esto implica de impresionismo y vaguedad, efectos propios de la estética modernista y simbolista.

La estrofa en torno a la cual fluctúa esta irregularidad en Crepusculario es por lo general el dístico, que tiene como emblema central el célebre «Farewell», aunque ya la composición que abre el libro, «Inicial», es de este tipo, y la irregularidad se produce en la última estrofa que sustituye el dístico por un terceto. Este poema propone un arranque solemne, dejando bien fijada la métrica desde el principio. Su única peculiaridad es que no hace 
sinalefa en el v. 1 en ninguno de los dos lugares posibles: «He-ido-ba-jo-He-lios» (lo mismo en el borrador: IV, 188), para destacar la extrañeza mítica del nombre, y para inaugurar un ritmo solemne y un tanto sorpresivo.

No obstante, aunque Neruda ha distribuido gráficamente su poema como tres dísticos más un terceto, el poema puede interpretarse como un único bloque en que se alternan versos con rima en -ante y -ente, con la única irregularidad de que el verso penúltimo repite la rima en -ante del anterior en lugar de conservar la alternancia. Sería difícil, por tanto, hablar de dísticos puros, ya que la continuidad de la rima obliga a realizar un enlace entre las diversas estrofas gráficas como si estuviéramos ante un todo sin divisiones.

«Sensación de olor» sería un poema regular en dísticos alejandrinos con alternancia de rimas en -ancia e -ila del tipo de «Inicial», si no tuviera una suerte de estribillo de apertura y cierre formado por dos trisílabos, estructura métrica que no varía desde el borrador (IV, 177). Estos versillos constituyen el encuadre de un poema regular. El tono impresionista del texto propicia tal ruptura métrica para oponerse a la solemnidad que caracteriza a los dísticos alejandrinos. Cada uno de los versos del estribillo genera, además, la rima de los dísticos alejandrinos.

En «El estribillo del turco» vemos también un diseño inicial sobre el que se establecen variaciones: pareados de rima consonante. Rompen esta regla la estrofa 9 que es un terceto monorrimo en consonante, como la que le sigue. La estrofa 17 tiene nominalmente tres versos:

\section{Y no temer. Y no pensar. \\ Dar \\ para volver a dar.}

pero la podemos considerar como un metro encabalgado y pensar que «Dar» va con el tercer verso, aunque la rima parece indicar la necesidad de dejarla como palabra-verso. La última estrofa es también un terceto, pero parece que, por la disposición de la rima, hay que considerar que el verso aislado al final forma parte de esta estrofa dando lugar a un serventesio. 
Pero lo realmente llamativo de esta composición es que la medida de los dísticos varía continuamente. Por poner sólo unos ejemplos, la primera estrofa está formada por la unión de un endecasílabo dactílico y un eneasílabo; la segunda por un decasílabo $(5+5)$ más un endecasílabo dactílico; la tercera por un dodecasílabo $(5+7)$ más un endecasílabo dactílico; la cuarta por dos endecasílabos dactílicos; la quinta por un endecasílabo dactílico más un dodecasílabo $(6+6)$; la sexta, séptima y octava por dodecasílabos (6+6), etc. Dominan los dodecasílabos de hemistiquios simétricos y el endecasílabo dactílico, pero la medida de los versos es altamente irregular, por lo que la unidad compositiva del poema viene dada por el patrón estrófico: pareados consonantes, que el poeta, además, rompe cuando lo necesita para la expresión.

«Farewell» presenta el mismo diseño de construcción en dísticos, pero esta vez la rima es arromanzada, asonante en los pares, lo que nos hace dudar de nuevo, como en «Inicial», si la distribución en dísticos es una mera estrategia gráfica. De nuevo aquí Neruda introduce excepciones al patrón que él mismo se fija de regularidad. El primer verso de la segunda parte aparece aislado y marca el principio de la rima, con la sensación de que falta un verso antes de él, de que el lector accede al poema cuando el discurso ya había comenzado. En cuanto a la medida de los versos es completamente regular en la primera parte: endecasílabos, la segunda varía entre el heptasílabo, el eneasílabo y el endecasílabo; la tercera alterna endecasílabos y heptasílabos, con la irregularidad del primer verso que es decasílabo (a no ser que no hagamos la sinalefa entre «Amo-el»); la cuarta parte alterna eneasílabos y heptasílabos, excepto el dístico final, que es endecasílabo; la última parte está compuesta por dísticos alejandrinos, excepto el último verso, que es un heptasílabo, o el primer hemistiquio de un alejandrino, como señal del truncamiento vital que supone la despedida para siempre, en un remedo icónico del adiós.

«Maestranzas de noche» está también formado sobre el patrón de los dísticos, en este caso alejandrinos, con alguna irregularidad, como es la reducción a un hemistiquio del segundo verso de la quinta estrofa, y el tercero de la sexta estrofa (como 
aparece ya en el borrador: IV, 183-4). De nuevo en este poema la disposición de las rimas nos hace pensar en una estructura real (frente a la gráfica) de serventesios, pues las dos primeras estrofas riman en asonante: $\mathbf{A B A B}$, las dos siguientes en consonante: $\mathbf{A B A B}$ y las dos últimas riman en asonante las posiciones impares y en consonante las pares, con la particularidad de que el serventesio sería en realidad un quinteto con el añadido de un verso inicial de rima $\mathbf{A}$. No obstante, este análisis deja fuera de juego la quinta estrofa que no formaría parte de una unidad mayor y, además, rima en asonante, en su segundo verso, con el supuesto serventesio anterior.

«Mariposa de otoño» se organiza igualmente en torno al dístico con rima consonante en las posiciones pares, aunque se intercalan varias estrofas de tres versos que rompen la regularidad del resto. La base métrica es el eneasílabo, que aparece variado con algún pentasílabo, para dar esa sensación juguetona y móvil de la mariposa. La rima, como digo, se mantiene en los pares en -ece (con la variante gráfica -ese), excepto en la tercerilla formada por la estrofa quinta, que tiene rima autónoma. A veces incluso riman las posiciones impares, y así en las estrofas 2, 3 y 4 asistimos a una rima alterna en -ada y -ece, que se retoma en la estrofa sexta tras el paréntesis de la quinta para desaparecer en el resto del poema.

Pero la mayor curiosidad de este poema viene dada por el hecho de que dos de las cuatro tercerillas introducidas aquí no son en realidad estrofas de tres versos: constituyen ejemplos claros de medida partida. La séptima estrofa, aunque dividida gráficamente en tres versos, está compuesta en realidad por dos endecasílabos, como se lee efectivamente en la estrofa 12 que le hace eco: «Pasó la hora de las espigas. / El sol, ahora, convalece». La estrofa final puede leerse como una tercerilla formada por un eneasílabo, un pentasílabo y un hexasílabo, como pide la rima, o como la suma de un eneasílabo y un endecasílabo considerando los dos versos finales como uno solo.

«No lo había mirado» está compuesto de nuevo por dísticos de endecasílabo y su pie quebrado (pentasílabo o heptasílabo). La rima es asonante en las posiciones pares, lo que nos vuelve a hacer pensar en la pertenencia de los dísticos a unidades mayores. 
El último verso, que parece quedar suelto, forma parte en realidad de la estrofa anterior, como indica la estructura de la rima, dando lugar de nuevo a la aparición de una medida real partida entre dos versos gráficos: «entró en su corazón. Y vamos juntos»: un endecasílabo perfecto.

«La muerte de Melisanda» son dísticos eneasílabos con rima de romance, excepto la penúltima estrofa que está compuesta por un terceto de rima $\mathbf{A A B}$, siendo el último verso el que guarda la asonancia y rimando los otros dos en consonante.

Según se ve, el dístico constituye una de las líneas vertebrales de construcción de los poemas en Crepusculario. Si tenemos en cuenta que muchos de los dísticos riman entre sí en las posiciones pares vemos que éstos pueden interpretarse como una secuencia de serventesios. De hecho, la otra estrofa en torno a la cual suele orbitar la irregularidad en Crepusculario es el serventesio, como era de esperar.

«Amor» sería completamente regular: serventesios alejandrinos, si no fuera porque la última estrofa está dispuesta gráficamente de manera que cada hemistiquio ocupa un solo verso, dando una estrofa de 6 versos (o con un séptimo escalonado). Ello se debe a que Neruda decide hacer rimar en este caso todos y cada uno de los hemistiquios, además del efecto icónico propiciado por el escalonamiento:

amarte más

y más

Volvemos a encontrar un fenómeno que ya nos ha salido al paso, el hecho de que cuando, por razones expresivas, se produce un conflicto entre la medida del verso y la rima, Neruda da preferencia al efecto expresivo de la rima y parte lo que, de otra forma, sería un metro entero.

«Barrio sin luz» pretende ser una composición de serventesios endecasílabos con rima asonante en los pares, con la única peculiaridad de incluir de vez en cuando un pie quebrado en eneasílabos (vv. 11 y 12), heptasílabo (v. 8) y pentasílabo (v. $15)$. 
Se puede considerar que «Grita» fluctúa también en torno al serventesio como patrón métrico central. Sin embargo, la segunda estrofa está formada por cuatro heptasílabos con rima asonante: aa-a, la tercera y cuarta por dos versos heptasílabos y dos alejandrinos, con rima arromanzada y de serventesio, respectivamente. Esta anomalía tiene un efecto icónico al principio de la estrofa tercera: «Amor, deshace el ritmo / de mis aguas tranquilas». La estrofa final es nominalmente de seis versos, pero podríamos formar un serventesio agrupando en dos alejandrinos los cuatro primeros heptasílabos. Neruda mantiene esta separación por la posibilidad, de nuevo, de rimar en asonante todos los hemistiquios siguiendo el patrón: aabaBB:

$$
\begin{aligned}
& \text { Amor-llegado que hayas } \\
& \text { a mi fuente lejana, } \\
& \text { tuérceme las vertientes, } \\
& \text { críspame las entrañas. }
\end{aligned}
$$

Y así una tarde - Amor de manos cruelesarrodillado, te daré las gracias.

El poema «Amigo» tiene predominio del serventesio. Su primera parte es un serventesio con la particularidad de que los dos primeros versos son endecasílabos, el tercero alejandrino y el último un tridecasílabo: «con sus blancas avenidas y sus canciones» analizable como alejandrino con cesura léxica: «con sus blancas avé / nidas y sus canciones». La tercera parte está compuesta por dos serventesios alejandrinos de rima asonante más un dístico cuyo último verso rima en asonante con la estrofa anterior. La parte segunda es la que escapa completamente a este esquema para formar una estrofa de siete versos endecasílabos que responderían al patrón del sexteto $\mathbf{A B B A C C}$ si no fuera porque el verso quinto queda suelto de rima.

«Me peina el viento los cabellos» tendría como base el serventesio asonante en eneasílabos, con la particularidad de que los pares riman todos en -á. Se trata, pues, de eneasílabos, que comienzan formando serventesio asonantados y acaban con dísticos (a partir de la cuarta estrofa) cuyo verso par sigue la asonancia -á sin que rime el impar, aunque en las dos últimas estrofas 
puede atisbarse un esbozo de serventesio, pues riman en asonante tanto par como impar: entre-repente, eternidad-cantar.

«La tarde sobre los tejados» a pesar de la sutilidad de su estructura gráfica, que recuerda a Verlaine, incluso por el ambiente, tiene también como base la estrofa de cuatro versos, que es la que predomina, principalmente en su parte central. La primera estrofa está compuesta por dos eneasílabos y dos tetrasílabos en alternancia, teniendo en cuenta que los versos 2 y 3 forman en realidad un tetrasílabo distribuido en dos líneas para resaltar el movimiento icónico de caída:

\section{La tarde sobre los tejados \\ cae \\ y cae...}

El primer verso de la segunda estrofa es un eneasílabo, pero resulta endecasílabo si le añadimos el siguiente. No obstante, en su disposición actual mantiene la estructura del serventesio arromanzado. Lo mismo pasa con la estrofa siguiente en la que podemos entender que los versos finales forman en realidad un eneasílabo. La última estrofa es claramente un eneasílabo más un pentasílabo. Vemos, por tanto, en este poema que domina el eneasílabo pero la estructura estrófica apenas deja entrever una tendencia hacia el serventesio arromanzado.

«Sinfonía de la trilla» tiene dos partes, que tienden a las estrofas de cuatro versos de distinta manera. La primera parte, regular, está compuesta por cuatro serventesios eneasílabos en cuyo centro se inserta un estribillo dividiendo la estrofa en dos mitades. Después viene una serie de serventesios endecasílabos excepto los seis últimos versos que son tres dísticos que siguen la estructura de rima del serventesio. Al final se retoma el esquema primero con estribillo con la diferencia que la última estrofa usa el estribillo como último verso ${ }^{5}$.

\footnotetext{
$\overline{5}$ «Tal contradicción no sintetizada, sensible en el título mismo del poema, se despliega interiormente en el contraste entre las partes con estribillo, que constituyen un cierto cuadro descriptivo - muy exiguo, sin duda- de la actividad campesina, y el cuerpo central de la composición, métricamente diverso, que es más bien un himno lírico del poeta a las fuerzas de la naturaleza, el sol y el campo. En esta parte, precisamente, resulta visible cómo el fenómeno colectivo del trabajo es
} 
«Playa del sur» está formado igualmente por serventesios eneasílabos de rima asonante y consonante, con la particularidad de que en ocasiones ni siquiera se conserva el esquema de la rima alterna y sólo riman los pares. Las tres estrofas finales son tres dísticos con rima en los pares. «La cabellera», del ciclo «Pelleas y Melisanda», está compuesto por eneasílabos agrupados en serventesios arromanzados, pero de rima consonante, con la particularidad de que las dos últimas estrofas son tercetos con un curioso encadenamiento: AAB CBC.

Comprobamos, pues, que la irregularidad en Neruda se basa principalmente en la relajación en diversos grados de los patrones tradicionales del serventesio y el dístico, el primero muy propio de la métrica modernista y el segundo una preferencia particular del poeta, aunque probablemente esté actuando en esta elección también la tradición francesa, que vertió gran parte de su lírica en pareados alejandrinos.

Existen, en menor medida, otras estrofas que marcan el patrón ideal en torno al cual se realizan variaciones. Tomando estrofas de tres versos como base estructuradora tenemos «Morena, la Besadora», tercerillas octosílabas sin encadenar, que emplea como pie quebrado el tetrasílabo en el último verso de cada estrofa impar (excepto en la estrofa 6, que es un pentasílabo). Pero esta regularidad que el propio poeta se impone, viene quebrada en las tres últimas estrofas. Aunque la estrofa antepenúltima es gráficamente una tercerilla, sin embargo, podemos leerla como un dístico de dos octosílabos: «Besadora, dulce y rubia, / me iré, te irás, Besadora», forma estrófica efectiva de la penúltima agrupación del poema. La última estrofa del poema es directamente una cuarteta, con rima aaab, y con los tres últimos versos heptasílabos. En este poema se ve especialmente claro cómo Neruda no usa como horizonte de regularidad un patrón ya fijado por la tradición, sino que él mismo se impone la regularidad que después traiciona, lo cual constituye una verdadera innovación.

«El ciego de la pandereta» empieza igualmente ciñéndose al patrón del terceto endecasílabo sin encadenar. En la tercera estrofa, sin embargo, el último verso es un hexasílabo. Las tres

absorbido por la subjetividad poética, cómo la trilla se convierte en mero estímulo para la sinfonía» (Concha, 1972: 88). 
últimas estrofas son las que presentan la irregularidad mayor pues nominalmente son dos serventesios arromanzados más un dístico que rima con ellos. No obstante, de estas estrofas la primera puede ser un terceto, pues los dos primeros heptasílabos son susceptibles de leerse como un alejandrino. En esta última parte toda la rima es arromanzada en -é.

En el poema «Oración» es el sexteto eneasílabo la base de la composición métrica, con el esquema $\mathbf{A A B C C B}$, forma de arte mayor empleada con relativa frecuencia por Darío (normalmente en su variante aguda, como la famosa «Sonatina»). Este patrón estrófico es respetado con excepción de la quinta estrofa, en que el verso que ocuparía el quinto puesto está desglosado en tres tetrasílabos de estructura paralela, siendo el segundo de ellos el portador de la rima y rimando los otros dos entre sí:
y va enredando en su camino
el mal dolor, el agrio sino
y desnudando la raigambre
de las mujeres que lucharon
y cayeron
y pecaron
y murieron
bajo los látigos del hambre

También hay vacilaciones en la medida, pues los versos 3 y 7 no pueden ser más que octosílabos, lo que nos da la idea de que el poeta actúa por aproximación a su esquema ideal. En la penúltima estrofa el último verso es un pentasílabo que actúa como pie quebrado del eneasílabo. Además, el eneasílabo que utiliza no tiene uniformidad en la acentuación, lo que da un aspecto un tanto desaliñado al ritmo y permite que se cuelen, sin llamar mucho la atención, los octosílabos que hemos detectado.

«Si Dios está en mi verso» tiene la apariencia de poema libre, sin embargo los tres primeros versos pueden leerse como dos endecasílabos tradicionales de dos maneras: «Perro mío, si Dios está en mi verso»o «Si Dios está en mi verso Dios soy yo». El resto de los versos son endecasílabos excepto el quinto que es pentasílabo. La necesidad de fundir de alguna manera en una 
sola unidad los tres primeros versos viene pedida por la estructura de la rima, que parece responder al patrón del romance en aguda.

Por fin, la «Canción de los amantes muertos» es una composición más libre en que estrofas de dos versos eneasílabos por lo general sin rimar se suceden con la intercalación de un estribillo «Perdónalos, Señor!». Además de estas formas tenemos dos poemas formados por un solo verso, alejandrino en ambos casos: «Mi alma», de corte verleniano y «Agua dormida».

Tras esta descripción de la métrica de Crepusculario podemos sacar algunas conclusiones a las que ya apuntaba en mi introducción. En primer lugar, Neruda no se propone una ruptura brusca con la tradición métrica del Modernismo, en especial con el modelo de Rubén Darío. Más bien parece que pretende llevar un paso más allá las innovaciones métricas que había introducido el Modernismo pero sin romperlas, es decir, sin llegar al ametricismo del verso libre, como sí hará en El hondero entusiasta, bajo la influencia de Sabat Ercasty.

Neruda utiliza principalmente patrones métricos propios del modernismo, pero aun cuando usa estos patrones tradicionales introduce alguna particularidad en su estructura. Lo más corriente, como hemos visto, es que varíe sobre un metro regular, bien heredado de la tradición, bien de una regularidad impuesta por él mismo. Esto se hace generalmente por razones expresivas y de coherencia contenido-forma. La ruptura de un esquema estrófico predeterminado por el propio poeta estaba ya en las «Letanías de nuestro Señor Don Quijote» de Rubén Darío que establece un sexteto agudo como estrofa que después rompe él mismo por razones expresivas (Paraíso, 1985: 132-134).

En esquema: 
INCIERTAS ESTANCIAS...

\begin{tabular}{|c|c|c|c|c|}
\hline Versificac. Libre & \multicolumn{4}{|l|}{$\begin{array}{l}\text { «Los jugadores» } \\
\text { «Final» }\end{array}$} \\
\hline \multirow[t]{8}{*}{$\begin{array}{l}\text { Versificac. } \\
\text { Regular }\end{array}$} & \multirow[t]{6}{*}{ Tradicional } & Soneto alejandrino & \multicolumn{2}{|c|}{$\begin{array}{l}\text { «Esta iglesia no tiene»; «Pantheos» } \\
\text { «Viejo ciego llorabas»; «El nuevo soneto a } \\
\text { Helena» }\end{array}$} \\
\hline & & \multirow[t]{3}{*}{ Serventesio } & Alejandrino & $\begin{array}{l}\text { «Ivresse»; "Aromos ru- } \\
\text { bios en los campos de } \\
\text { Loncoche»; «Dame la } \\
\text { maga fiesta»; «Saudade»; } \\
\text { «Aquí estoy con mi pobre } \\
\text { cuerpo»; «Hoy, que es el } \\
\text { cumpleaños de mi herma- } \\
\text { na»; «Mujer, nada me has } \\
\text { dado»; «Tengo miedo»; } \\
\text { «El pueblo»; «El coloquio } \\
\text { maravillado» }\end{array}$ \\
\hline & & & De $8+8$ & «El castillo maldito» \\
\hline & & & Endecasílab. & «Campesina» \\
\hline & & Pareado & \multicolumn{2}{|l|}{ «Melisanda» } \\
\hline & & Terceto & \multicolumn{2}{|c|}{$\begin{array}{l}\text { «El padre» } \\
\text { «El encantamiento» }\end{array}$} \\
\hline & & Silva & \multicolumn{2}{|l|}{ «Puentes» } \\
\hline & No tradicional & Dístico & \multicolumn{2}{|c|}{$\begin{array}{l}\text { «Mancha en tierras de color» } \\
\text { «Poema en diez versos» }\end{array}$} \\
\hline \multirow[t]{5}{*}{$\begin{array}{l}\text { Versificac. } \\
\text { Irregular }\end{array}$} & \multirow[t]{3}{*}{$\begin{array}{l}\text { Sobre formas } \\
\text { tradicionales }\end{array}$} & Serventesio & \multicolumn{2}{|c|}{$\begin{array}{l}\text { «Amor»; «Barrio sin luz»; «Grita»; «Amigo»; } \\
\text { «Me peina el viento los cabellos»; «La tarde sobre } \\
\text { los tejados»; «Sinfonía de la trilla»; «Playa del } \\
\text { Sur»; «La cabellera» }\end{array}$} \\
\hline & & Terceto & \multicolumn{2}{|c|}{ «El ciego de la pandereta» } \\
\hline & & Sexteto & \multicolumn{2}{|l|}{ «Oración» } \\
\hline & No tradic. & \multicolumn{3}{|c|}{ «Morena, la besadora» (tercerillas) } \\
\hline & Dístico & \multicolumn{3}{|c|}{$\begin{array}{l}\text { «Inicial»; «Sensación de olor»; «El estribillo del turco»; «Farewell»; } \\
\text { «Maestranzas de noche»; «Mariposa de otoño»; «No lo había mirado»; } \\
\text { «La muerte de Melisanda»; «Canción de la amante»; «Si Dios está en } \\
\text { mi verso» (¿?) }\end{array}$} \\
\hline
\end{tabular}


Como se ve en el esquema, dominan los patrones regulares tradicionales y las irregularidades practicadas sobre estos mismos patrones. En la división entre formas irregulares a partir de moldes clásicos o de patrones inventados he situado como categoría aparte los dísticos irregulares porque no se puede saber si en ellos se varía sobre una forma tradicional, debido al escaso cuerpo material que tiene la estrofa. Este patrón presenta una gran versatilidad, lo que lo hace idóneo para practicar diversos juegos métricos, no siendo el menor de ellos el hecho de fomentar su proximidad al serventesio cuando se hacen rimar los dísticos de manera alterna a lo largo de una misma composición. Este esquema puede servir, además, como un primer acercamiento a la distinción entre verso libre, regular e irregular en otros poetas.

Todo esto nos enseña, a efectos de teoría, que la métrica tradicional es en realidad un decantado de una serie de formas regulares que se han usado históricamente; a la vez, la regularidad constituye el ideal fijado de una serie de aproximaciones a tal norma. Los juegos que Neruda introduce sobre la regularidad nos indican que dicha regularidad es un objetivo a conseguir $\mathrm{y}$ en torno a ella pueden darse diversas variaciones. En el momento en que el metro no pueda ajustarse a ningún patrón ideal, estamos en el terreno de la versificación libre, que sería distinta de la regular e irregular precisamente no porque su medida no se ajuste a la tradición sino porque no tiende de ninguna manera a ningún patrón estrófico ni métrico como ideal. Sería una versificación amétrica. Se ve claro, por ejemplo, en «El estribillo del turco», cuyos versos fluctúan grandemente en la medida $y$, sin embargo, el mantenimiento del dístico como unidad estrófica a lo largo de la obra nos impide hablar con propiedad de verso libre.

La versificación libre se caracterizaría en concreto por no tener en cuenta el ritmo formal sino el ritmo de la idea, como dice Huidobro en su introducción a Adán: «La idea es la que debe crear el ritmo y no el ritmo a la idea como en casi todos los poetas antiguos». La propuesta de que el ritmo debe estar al servicio del sentido puede ser sostenida incluso por poetas muy tradicionales métricamente. Ahí tenemos el caso de José Martí, 
que hablaba en la introducción de sus Versos libres de que «así como cada hombre trae su fisonomía, cada inspiración trae su lenguaje», y sus Versos libres resultan ser tiradas de endecasílabos clásicos. Huidobro se refiere, por tanto, a que el ritmo de las ideas sustituye al ritmo métrico y no que lo crea. Pablo Neruda está, en sus inicios como poeta, más cercano a la idea de libertad poética de Martí: jugar con la tradición métrica para someterla a sus particulares necesidades expresivas. De hecho Neruda sólo introduce el verso libre en dos ocasiones, y en una de ellas precisamente para hacer un poema de «ideas» en el sentido de Huidobro, una poética, en la composición final de Crepusculario.

\section{Neruda antes de Neruda}

Para comprobar hasta qué punto los rasgos métricos de Crepusculario que acabamos de estudiar son realmente característicos del primer Neruda, hay que completar este estudio con un análisis aunque sea aproximativo (debido a la cantidad ingente del material) de la poesía anterior y contemporánea de Crepusculario recogida en los cuadernos inéditos nerudianos y en las publicaciones en revistas. Ello nos dará la medida de las intenciones de Neruda sobre el detectado rechazo inicial a las soluciones vanguardistas y versolibristas y su adscripción a una renovación interna de las formas modernistas.

Para realizar esta labor de manera sistemática dividiré el material de la siguiente forma. Analizaré primero los poemas publicados en revistas o enviados a concursos, distinguiendo entre los regulares y los irregulares, y lo mismo haré con los no publicados, para comprobar cuál es la proporción de regularidad e irregularidad en ambos casos, lo que arrojará luz sobre la imagen pública que Neruda quería ofrecer de su poesía en un primer momento, a la vista de lo que daba a la impresión y lo que se reservaba para sí.

Como una primera aproximación se puede decir que los poemas publicados en revistas o enviados a concursos por el joven Neruda son por lo general bastante regulares. Dominan, como no podía ser de otra manera, los serventesios, principalmente alejandrinos, como vimos que ocurría en Crepusculario. 
Son serventesios regulares en alejandrinos: «Iré por mi camino» (IV, 57); «Esperanza» (IV, 58); «No te ocultes, araña» (IV, 5859); «Los buenos» (IV, 61-62); "Cuando se deshizo el encanto» (IV, 75); «Comunión ideal» (IV, 78-80); «Yo te soñé una tarde» $(\mathrm{IV}, 82)$; «Gracias (1)» (IV, 120). No obstante detectamos alguna ruptura de la regularidad en este patrón: «La pequeña alegría» (IV, 146-7); «Mis ojos» (IV, 55), un temprano poema formado por tres serventesios alejandrinos con el último verso de cada estrofa en eneasílabo como pie quebrado; o «El salmo del amor perdido» $(\mathrm{IV}, 222)$.

Tenemos serventesios endecasílabos regulares en: «La canción del árbol viejo» (IV, 59-60); «Una tarde» (IV, 61), con la particularidad de que el último verso de cada estrofa es alejandrino; «El deseo de irse» (IV, 70); «La canción de la fiesta» (IV, 227-8), con rima asonante en los impares y consonante en los pares y con todos los endecasílabos dactílicos, quizá por influencia de Pórtico, de Darío.

La siguiente estrofa más usada es el soneto, que en proporción abunda más en los cuadernos de lo que lo hará en Crepusculario. Tenemos sonetos alejandrinos regulares en: «Caminando» (IV, 60); «El dolor del viajero» (IV, 62); «De mi vida de estudiante (1)» (IV, 64); «El momento sereno» (IV, 72-3); «En la buena canción» (IV, 76); «Desde que te fuiste» (IV, 77); «Desde mi soledad» (IV, 85-7), un tríptico compuesto por dos sonetos alejandrinos en los extremos y uno eneasílabo en el centro; «El cuento ingenuo» (IV, 93-4); "Primavera en la noche» (IV, 104-5); «Elogio de las manos» (IV, 166-7), un tríptico de tres sonetos alejandrinos, excepto el primer cuarteto del primer soneto, que es endecasílabo. Como variante encontramos un soneto dodecasílabo (6+6) en «Sensación de clase de Química» (IV, 165).

Por el contrario, los dísticos, la forma estrófica privilegiada en Crepusculario, apenas aparecen en los poemas publicados procedentes de los cuadernos. Sólo tenemos «Primavera (I)» (IV, 56), compuesto por 5 pareados alejandrinos regulares. El terceto se usa también en una sola ocasión en «Esta crueldad nuestra» (IV, 76-7) formado por tres tercetos alejandrinos con rima $\mathbf{A A B} \mathbf{C C B} \mathbf{D B D}$.

En cuanto a series regulares contamos: «El llanto por los tris- 
tes» (IV, 63), tres tiradas de endecasílabos; y «Cómo te presiento» (IV, 64-5), romancillo en hexasílabos con rima en los impares. Este poema constituye una excepción porque el primer Neruda no es muy aficionado al arte menor; ambos poemas muestran la novedad de hacer una rima de tipo arromanzada pero en las posiciones impares.

Dos silvas cierran este apartado: «A los poetas de Chile» (IV, 225-7), un largo poema reivindicativo en el que dominan los endecasílabos y su pie quebrado el heptasílabo; con todo, el primer verso, formado por un nombre propio, «Joaquín Cifuentes Sepúlveda», es un octosílabo, lo que sirve para poner en primer plano la figura del poeta preso al que se dedica el poema; $y$ «Los cuentos viejos» (IV, 154-5), con mezcla de alejandrinos, heptasílabos y eneasílabos de rima consonante.

Frente a esta abundancia de poemas regulares (la mayor parte serventesios y sonetos) publicados, comprobamos que los poemas publicados de carácter irregular son más escasos y se agrupan hacia fechas cercanas a la publicación de Crepusculario.

Un primer nivel de irregularidad afecta a la mezcla de estrofas: «La mirada» (IV, 67-8), tres serventesios eneasílabos y dos tercetos finales con rima asonante, como si se tratara de un soneto al que se ha añadido un cuarteto; «Estos quince años míos» (IV, 87-8) compuesto por cinco sextetos alejandrinos con rima $\mathbf{A A B C C B}$ y un terceto como coda con la rima $\mathbf{A A B}$, cuyo último verso rima con el último de la estrofa anterior.

Mayor irregularidad presentan los siguientes poemas: «Primavera (2)» (IV, 179), que aunque gráficamente parece una serie continuada, está compuesto por cuartetas asonantes en octosílabos, pero a partir del verso 9 la cuarteta se descompone y sólo es octosílabo el verso segundo, siendo el resto bisílabos y conservando la rima. La composición acaba con un dístico cuyo último verso rima en asonante con el último de la cuarteta. Es el tipo de irregularidad que se detecta en Crepusculario, aunque ahí es raro el uso del octosílabo. Lo mismo ocurre con «Un hombre anda bajo la luna» (IV, 230-1), una aproximación a la cuarteta octosílaba de rima consonante, con adelgazamiento de versos y partición de medidas. La versificación libre sólo aparece una vez: «Los minutos sencillos» (IV, 215-6), un tríptico con tendencia al versículo. 
Se comprueba, pues, que los poemas irregulares y libres publicados por el propio Neruda son realmente escasos, frente a la abundancia de los regulares publicados. Ello nos habla de la tendencia que veíamos en Crepusculario de asentarse formalmente en la estela del Modernismo como métrico virtuoso, desatendiendo a la vanguardia circundante. Se puede notar, de hecho, que cuanto más avanzamos en el tiempo más se van pareciendo los poemas de los cuadernos publicados a las irregularidades que caracterizarán Crepusculario. Es importante también tener en cuenta que de esta época más avanzada son los poemas en prosa «De los hombres que esperan» (IV, 218-20).

Vamos a comprobar ahora cómo, por el contrario, los poemas que el poeta decide no publicar contienen en su mayoría algún tipo de irregularidad y de innovación métrica. La gran abundancia de estos poemas hace que me limite a señalar las tendencias generales y me detenga en algún caso llamativo.

En un primer grado de irregularidad tenemos poemas que simplemente mezclan estrofas regulares: «El que se va» (IV, 66); «La vulgar que pasó» (IV, 97-8), tres cuartetos alejandrinos entre los que se intercalan dos sextetos: AABCCB; «Mi tríptico simbólico» (IV, 100-2); «En la ventana» (IV, 145); «Allegro en $a$ clarísima» (IV, 151); «Amanecer» (IV, 169); «Balada de la infancia triste» (IV, 172-3); «La maestrita aquella...» (IV, 175); «Himno al sol» (IV, 209-210); «Las lámparas» (IV, 210-1); «Laus Deo» (IV, 221-2); y «Dolor» (IV, 114-5), uno de los pocos casos en que Neruda abandona la rima en esta etapa.

Me interesa destacar «Lluvia lenta» (IV, 122-3), formado por dísticos enlazados por la rima que se agrupan a veces en serventesios, con lo que vemos ya esa tendencia de Neruda a jugar con la ambigüedad de los dísticos con rima alterna, interpretables como verdaderos serventesios que gráficamente se distribuyen de dos en dos.

Dentro de esta estrategia de mezclar metros tradicionales para formar nuevas combinaciones estróficas podemos encontrar, como curiosidad, disposiciones que se asemejan a un patrón conocido. Son sobre todo abundantes las formas que se acercan al soneto: «La emoción fugitiva» (IV, 78), que parece un soneto eneasílabo con un cuarteto de más; «Oh, la triste sonata de los 
males eternos» (IV, 94), que parece un soneto al que faltara el primer cuarteto; «Mi paraíso perdido» (IV, 99), que sería un soneto con dos dísticos en el lugar de los tercetos; "No me siento cambiar» (IV, 149-150), como un soneto al que se le han añadido dos cuartetos; e «Iniciación» (IV, 197-198), que sería un soneto si no fuera porque el último terceto está sustituido por un dístico.

Más complejo es «Mi juventud» (IV, 95-6), compuesto por dos serventesios alejandrinos (excepto el verso 7, heptasílabo) más un terceto y una estrofa final de cuatro versos de manera que la rima no cuenta el penúltimo verso sino el último pie quebrado, lo que daría una estructura perfecta de final de soneto: $\mathbf{A A B}$ CCB. La estructura se asemeja al soneto al que sobra un verso.

Un siguiente paso lo constituirían los poemas que se inician con una forma estrófica regular que después se pierde en el desarrollo del poema, como «Lo estéril» (IV, 115) y «La sinfonía brumosa» (IV, 116-7).

«Cansancio (2)» (IV, 116) parece ser la primera aparición del verso libre y sin rima, ya que las medidas varían ampliamente, aunque se detecta algún endecasílabo y alejandrino. De hecho la estrofa final estaría compuesta por cuatro alejandrinos si hiciéramos un cambio en el verso antepenúltimo y en lugar de «agitaron las alas los pájaros venenosos» dijera «agitaron las alas los venenosos pájaros». Esto nos puede hacer pensar que no se trata de un poema en verso libre sino de un esbozo sin acabar. Cosa que puede ocurrir también con «Velada familiar» (IV, 126), formado por la mezcla de versos de varias medidas con rima alterna en -á al principio, después se incluye un sexteto agudo que tiende al alejandrino y se cierra con un pareado que no se ajusta a medida alguna.

Con forma de silvas libres tenemos: «La estrofa humilde» (IV, 150-1); «Égloga simple» y «Otoño» (IV, 170-1); «Las puertas» (IV, 157-8), un híbrido entre los cuartetos y la silva; o «Proemio» (IV, 93), que tiene estructura de silva, aunque las rimas y su disposición nos hacen pensar en una estructura subyacente de serventesios.

Vemos, pues, que en los poemas no publicados Neruda juega en mayor medida a innovar, innovaciones que pasarán algunas 
a Crepusculario. No debemos olvidar, no obstante, que en los cuadernos podemos estar a veces ante versiones de poemas que después Neruda hubiera regularizado. Con todo, no puede ser un esbozo el poema «Apunte de primavera» (IV, 205) en que Neruda introduce un verso vertical a la manera de Huidobro, lo cual habla elocuentemente sobre la voluntad de no publicar este tipo de experimentos.

Al mismo tiempo vemos que Neruda se muestra más experimentador en estos poemas no publicados no sólo por lo que respecta a los patrones métricos, sino también en el uso de encabalgamientos notablemente violentos para la sintaxis: «y mis contentos con / el raro sortilegio» («Una luz irreal me alumbra en el camino», IV, 137); «dolor de vivir solos entre la gente y en / la vida toda» («Poeta», IV, 128-130); «un sentir en los labios, en los ojos y en / el recuerdo el retrato...» y «Por las calles enormes, desoladas y sin / aquel encantamiento...» («Lo mismo», IV, 112).

No faltan, sin embargo, entre los poemas no publicados abundantes muestras de metros regulares. Domina, con mucho, el soneto alejandrino (algunos con rimas asonantes) cuya cantidad, vuelvo a recordar, contrasta con los pocos que pasan después a Crepusculario, y que no listaré debido a su abundancia. Sorprende después la cantidad de sonetos dodecasílabos formados por dos hemistiquios simétricos: «De mi vida de estudiante (3)» (IV, 68-9); «Aquel» (IV, 69-70); «De mi vida de estudiante (4)» (IV, 73); «Los sonetos del diablo» (IV, 91-2), tríptico de sonetos dodecasílabos, excepto el último, que es alejandrino; «La busca» (IV, 168-9). A ellos hay que añadir uno con ritmo de seguidilla «El poeta que no es burgués ni humilde» (IV, 81-2). Hay, sin embargo, pocos sonetos endecasílabos, más propios de la tradición hispánica: «Deslumbramiento» (IV, 105); «Elegía de la pena que pasa» (IV, 161-2); «Manos de campesino» (IV, 189) con el primer serventesio endecasílabo y los demás alejandrinos; $\mathrm{y}$ «Ensoñación perdida» (IV, 85).

Es llamativo observar que esta avalancha de sonetos regulares no publicados abunda en los primeros momentos y su número va decreciendo según nos acercamos a la fecha de publicación de Crepusculario, donde hemos visto que este metro no está muy 
presente. Es como si Neruda en el proceso de aprendizaje, al tiempo que deja sin publicar los poemas más avanzados métricamente, va afianzando su técnica con formas altamente formalizadas, que debían representar para él puros ejercicios de estilo y en consecuencia va abandonando progresivamente.

La otra estrofa que domina en los poemas no publicados regulares es el serventesio en todas las medidas, pero a veces sometido a variantes y con abundante uso de la rima asonante, innovación que quizá hizo a Neruda pensar que no debían ser publicados. Igualmente, dejo de dar la lista debido a su abundancia. Con los serventesios ocurre como con los sonetos. Neruda puede decidir no publicarlos debido a que los considera meros juegos estilísticos, para probar la mano. De hecho, muchas veces no se sabe si son poemas completos o inicios de sonetos, o borradores de poemas más regulares. Aun manteniendo la regularidad, la alteración constante de las medidas y de las rimas que sufren estos poemas quizá los hacían inapropiados a los ojos de Neruda para su publicación, por no suficientemente regulares.

El dístico, la otra medida reina de Crepusculario, y que hemos visto que no era muy abundante entre los poemas publicados, tampoco lo es entre los no publicados en su forma regular: «Me botaré en el llanto más claro de mi vida» (IV, 148); «El liceo» (IV, 159-171); «La angustia» (IV, 174-5 y IV, 199); y «Como en la noche el pueblo duerme benditamente» (IV, 220-1).

Encontramos otras medidas en: «Nocturno» (IV, 53) donde el poeta establece como estrofa el quinteto, con rima ABACB, pero a veces en lugar del endecasílabo usa su pie quebrado, el heptasílabo; «Tedio» (IV, 96-7), tercetos monorrimos irregulares en la medida; «Poeta» (IV, 128-130), una larga silva de alejandrinos y heptasílabos con rima consonante y asonante; «Me bañé en las lumínicas aguas de tu mirada» (IV, 118-9), un extenso poema, una silva de alejandrinos, heptasílabos y endecasílabos de rima consonante; «Momento» (IV, 95), silva con rima asonante por lo general alterna; y «Morbosa lasitud que nos condena» (IV, 81 ), una serie de 9 endecasílabos con rima asonante de manera irregular.

Pero la prueba definitiva de que Neruda tiende a publicar sólo los poemas que le parecen más regulares en un primer momento 
es la constancia que tenemos de que regulariza al menos un poema para su publicación. El poema «Canción» (Neruda, 1980: 57) aparece en el manuscrito con una introducción irregular: «Pero ahora», seguida de una serie de eneasílabos de rima asonante en los pares. Cuando el poema se imprime en la revista Primavera, Neruda suprime esa pequeña irregularidad inicial y deja sólo la serie de eneasílabos, es decir, mantiene una estricta regularidad.

Varias conclusiones se pueden extraer de este recorrido por la métrica del primer Neruda. La más importante es su intención de prolongar la estética del Modernismo, por lo que respecta a la métrica, y renovarla desde dentro, rehuyendo del verso libre y dedicándose a introducir distintos tipos de irregularidades en los patrones métricos tradicionales. Para ello he propuesto una distinción metodológica entre verso regular, irregular y libre, que supone una novedad en la descripción métrica que se puede aplicar a otros autores, especialmente a autores postmodernistas que practican diversas variantes de la métrica regular e instauran irregularidades que no se pueden considerar versificación libre, pero tampoco completamente regular.

\section{Referencias}

Acuña, María Eugenia (1979), «Algunos rasgos poéticos de Crepusculario», en Repertorio Americano, Heredia, v. 5 n. 2, pp. 6-15.

Concha, Jaime (1972), Neruda (1904-1936), Santiago, Edit. Universitaria.

- (1974), «Proyección de Crepusculario», en Ángel Flores, Aproximaciones a Pablo Neruda, Barcelona, Ocnos, pp. 22-41.

Domínguez Caparrós (1993), Métrica española, Madrid, Síntesis.

- (2004), Diccionario de métrica española, Madrid, Alianza.

- (2005), Elementos de métrica española, Valencia, Tirant lo Blanch.

Jaimes Freyre, Ricardo (1912), Leyes de la versificación castellana, Buenos Aires, imprenta de Coni Hermanos.

Loyola, Hernán (1996), «Primera aproximación al uso del eneasílabo en Pablo Neruda», Revista chilena de literatura, 49, pp. 103-112.

Lugones, Leopoldo (1988), Lunario sentimental, ed. Jesús Benítez, 
Madrid, Cátedra.

Montes, Hugo (1974), Para leer a Neruda, Santiago, Francisco de Aguirre.

Navarro Tomás, Tomás (1968), Repertorio de estrofas españolas, New York, Las Américas Publishing.

- (1974), Métrica española. Reseña histórica y descriptiva, MadridBarcelona, Ediciones Guadarrama-Labor, 1974. $4^{\mathrm{a}} \mathrm{ed}$.

- (1982), Los poetas en sus versos: desde Jorge Manrique a García Lorca, Barcelona, Ariel.

Neruda, Pablo (1980), El río invisible. Poesía y prosa de juventud, Barcelona, Seix Barral.

- (2000-2002) Obras completas, Barcelona, Galaxia Gutenberg-Círculo de Lectores. 5 vols.

Paraíso, Isabel (1985), El verso libre hispánico: orígenes y corrientes, Madrid, Gredos, 1985.

Quilis, Antonio (1984), Métrica española, Barcelona, Ariel.

Tavani, Giuseppe (1964), «Per una lettura rimemica di una poesia di Pablo Neruda», Quaderni di letterature Americane, I, pp. 3-24.

Utrera Torremocha, María Victoria (2001), Historia y teoría del verso libre, Sevilla, Padilla Libros.

Woodbridge, Hensley C. y Zubatsky, David S., Pablo Neruda. An annotated Bibliography of Biographical and Critical Studies, New York, Garland Publishing, 1988. 